\title{
SEMI-SMOOTH POINTS IN SPACE OF OPERATORS ON HILBERT SPACE
}

\section{PAWEŁ WÓJCIK}

Abstract. The investigations of the smooth points in the operator spaces $\mathscr{K}(\mathscr{H})$ and $\mathscr{L}(\mathscr{H})$ were started in [J. R. Holub, Math. Ann. 201 (1973), 157-163] and [T. J. Abatzoglou, Math. Ann. 239 (1979), 129-135]. The aim of this paper is to present a description of semi-smooth points in the operator spaces $\mathscr{L}\left(\mathscr{H}_{1}, \mathscr{H}_{2}\right)$ and $\mathscr{K}\left(\mathscr{H}_{1}, \mathscr{H}_{2}\right)$.

Mathematics subject classification (2010): 46B20, 46B28, 46C50, 47L05.

Keywords and phrases: Hilbert space, space of operators, norm derivatives, semi-smoothness.

\section{REFERENCES}

[1] T. J. Abatzoglou, Norm Derivatives on Spaces of Operators, Math. Ann. 239 (1979), 129-135.

[2] C. Alsina, J. Sikorska, M. Santos Tomás, Norm Derivatives and Characterizations of Inner Product Spaces, World Scientific, Hackensack, NJ, 2010.

[3] S. S. Dragomir, Semi-Inner Products and Applications, Nova Science Publishers, Inc., Hauppauge, NY, 2004.

[4] J. R. Holub, On the Metric Geometry of Ideals of Operators on Hilbert Space, Math. Ann. 201 (1973), 157-163.

[5] P. M. MiLIČIĆ, Sur le semi-produit scalaire dans quelques espaces vectorial normès, Mat. Vesnik, 8(23) (1971), 181-185.

[6] P. M. MiLičıć, Sur les espaces semi-lisses, Mat. Vesnik, 36 (1984), 222-226.

[7] P. M. Miličíć, Sur la G-orthogonalité dans les espaces normés, Mat. Vesnik, 39 (1987), 325-334.

[8] D. SAIn, K. PAUl, A. MAL, A. RAY, A complete characterization of smoothness in the space of bounded linear operators, Linear and Multilinear Algebra, Volume 68, Issue 12, (2020), 2484-2494.

[9] P. Wóıсıк, Gateaux derivative of the norm in $\mathscr{K}(X, Y)$, Ann. Funct. Anal. 7 (2016), no. 4, 678-685.

[10] P. WóJCIK, Birkhoff orthogonality in classical M-ideals, J. Aust. Math. Soc. 103 (2017), 279-288.

[11] P. WóJCIK, Characterization of linear similarities through functional equation and mappings preserving orthogonalities, Linear Algebra Appl., 579, 2019, 206-216. 